\title{
Intrascleral Knotless Zigzag Suture Fixation of Four-Haptic Hydrophilic Acrylic Foldable IOL: Clinical Outcomes
}

\author{
Nisa Silva $\mathbb{D}^{1, *}$ \\ André Ferreira $\mathbb{I D}^{1,2, *}$ \\ Natália Ferreira' \\ Bernardete Pessoa (D) 1,3 \\ Angelina Meireles $\mathbb{D}^{1,3}$ \\ 'Department of Ophthalmology, Centro \\ Hospitalar Universitário do Porto, Porto, \\ 4099-00I, Portugal; ' $U n i t$ of Anatomy, \\ Department of Biomedicine, Faculty of \\ Medicine of University of Porto, Porto, \\ 4200-319, Portugal; ${ }^{3}$ Department of \\ Ophthalmology, Instituto de Ciências \\ Biomédicas Abel Salazar, University of \\ Porto, Porto, 4050-3I3, Portugal \\ *These authors contributed equally to \\ this work
}

Background: The main options for intraocular lens (IOL) placement without capsular bag support and/or zonular weakness are iris-fixated IOL and scleral-fixated IOL (SFIOL).

Purpose: To describe the surgical technique and the outcomes of intrascleral knotless zigzag suture fixation of Akreos AO60 foldable IOL.

Methods: Retrospective cohort study of consecutive cases.

Results: Ninety-nine eyes of 92 patients were retrospectively studied. The mean age was $72.1 \pm 15.2$ years (range 18-94), and the median follow-up duration was 19.5 months (range $3-81$ ). The best-corrected visual acuity improved from a mean \pm SD of $1.34 \pm 0.70$ logarithm of the minimum angle of resolution (logMAR) units at baseline to $0.49 \pm 0.56 \log$ MAR at the end of follow-up $(\mathrm{p}<0.001)$. The mean \pm SD final SE was $-1.24 \pm 1.82$ diopters. The mean \pm SD prediction error was $-0.51 \pm 1.16$ diopters. The overall perioperative complications rate was $44.4 \%(n=44)$. The rate of complications requiring invasive treatment was $19.2 \%(n=19)$. The most common perioperative complications were ocular hypertension (OHT, 20.2\%, $\mathrm{n}=20$ ), and cystoid macular edema (CME, 15.2\%, $\mathrm{n}=15)$. The rate of IOL dislocation was $7 \%(\mathrm{n}=7)$.

Conclusion: This knotless technique avoids the risks of haptics fixation but is more prone to IOL dislocation in cases of suture deterioration. Past ophthalmic history needs to be carefully considered in candidates who underwent SFIOL implantation.

Keywords: intraocular lens, scleral fixation, knotless, cataract, lens luxation

\section{Introduction}

Phacoemulsification with intraocular lens (IOL) placement in the capsular bag is the gold standard for cataract surgery with adequate capsular support. When an adequate capsule support is absent and/or zonules are weak or absence, the main options are iris-fixated IOL (IFIOL) and scleral-fixated IOL (SFIOL), with the expectancy of similar outcomes. ${ }^{1-3}$ Some surgeons would rather to implant a SFIOL to ensure a more physiologic position and to avoid the risk of corneal decompensation. ${ }^{4,5}$ However, the scleral fixation is technically challenging and not devoid of risks.

Over the last years, many surgical techniques have been described, and novel IOL designs have increased the armamentarium of SFIOLs. The method of fixating an IOL in the sclera may use sutures or not. The sutured techniques have been modified to incorporate scleral flaps or pockets to prevent the conjunctival erosion provoked by exposed knots. ${ }^{4}$ Alternatively, the knot can be avoided by running the
Correspondence: Nisa Silva Department of Ophthalmology, Centro Hospitalar Universitário do Porto, Largo do Prof. Abel Salazar, Porto, 4099-00I, Portugal

Tel +35I 222077500

Email nisapinhosilva@gmail.com 
suture through the partial thickness of the sclera in a zigzag pattern. ${ }^{6}$ Using thicker or other types of threads has been further suggested to reduce suture breakage and lens dislocation or tilt. ${ }^{7}$ The sutureless techniques using fibrin glue ${ }^{8}$ or scleral tunnels ${ }^{5,9-12}$ have gained popularity recently. While novel techniques have been introduced, IOL designs have also evolved. CZ70BD IOL ${ }^{13}$ (Alcon, Fort Worth, Texas), for example, includes eyelets to prevent the suture slippage and subsequent lens dislocation. Akreos $\mathrm{AO}^{14}{ }^{14}$ (Bausch \& Lomb, Rochester, New York) is a foldable IOL with eyelets, and its off-label use as a SFIOL has been reported. FIL SSF Carlevale IOL ${ }^{15}$ (Soleko, Italy) was specifically engineered for scleral fixation without sutures.

In our center, intrascleral knotless zigzag suture fixation of Akreos AO60 foldable IOL has been adopted as the standard surgery for eyes with poor capsular support. The present study aims to describe the surgical technique, functional outcomes and perioperative complications of intrascleral knotless zigzag suture fixation of Akreos AO60 foldable IOL.

\section{Methods}

This is a retrospective, observational, single-center study of consecutive eyes submitted to scleral fixation of AkreosAO60 foldable IOL using the knotless zigzag technique at Centro Hospitalar Universitário do Porto (CHUPorto), a tertiary center, from December 2013 to February 2021. All consecutive cases with a follow-up of at least 3 months were included. The enrolled eyes were divided into groups according to the etiology: spontaneous IOL dislocation, intraoperatively complicated cataract surgery, traumatic natural lens or IOL dislocation, or, rarely, other causes. The research adhered to the principles of the Declaration of Helsinki and its latest amendment (Brazil, 2013). All patients provided informed consent for treatment, and the study protocol complies with the requirements of the institute's committee ("Departamento de Ensino, Formação e Investigação") on human research.

\section{Clinical Data}

The clinical records were reviewed for demographic data, history of ocular and systemic diseases, indication for surgery, preoperative and postoperative best corrected visual acuity (BCVA), postoperative astigmatism and spherical equivalent (SE), and intraoperative and postoperative surgical complications. A comprehensive ophthalmic evaluation including BCVA and refraction, slit-lamp examination, measurement of intraocular pressure, and fundus examination was carried out at baseline and over the course of the follow-up. For statistical purposes, "counting fingers" was classified as 0.01 , "hand movement" as 0.005 and "light perception" as $0.0005 .{ }^{16}$ Visual acuity registered in decimals was converted to the logarithm of the minimum angle of resolution (LogMAR) equivalent. ${ }^{17}$ Refractive prediction error was calculated as the difference between postoperative objective refraction expressed as SE, and the predicted SE of the refraction was obtained from preoperative biometry (IOLMaster 500, Carl Zeiss Meditec AG) using SRK-T formula and assuming in-the-bag IOL positioning. Absolute prediction error was calculated as the absolute value of the difference between the postoperative subjective SE and the formula prediction error.

\section{Surgical Treatment}

All surgeries were performed by three senior vitreoretinal surgeons (A.M., N.F., and B.P.) of the Department of Ophthalmology of CHUPorto, all of them with more than 10-years' experience.

The Akreos AO60 (Bausch \& Lomb, Rochester, New York) is a single-piece four-haptic hydrophilic acrylic foldable intraocular lens (IOL) which is implanted inside the eye through a corneal incision as small as $1.8 \mathrm{~mm}$. This IOL contains an eyelet in each haptic to provide a fourfixation point, thereby guaranteeing good centration and stability. The overall diameter varies from 10.5 to $11 \mathrm{~mm}$ according to the diopter power (between +0 and +30 diopters). The IOL power was calculated using an A-constant of 118.5 , as recommended by the manufacturer. ${ }^{18}$

The intrascleral knotless zigzag suture fixation of Akreos AO60 foldable intraocular lens (IOL) technique is illustrated in Figure 1 and a postoperative slit-lamp photography is depicted in Figure 2. All cases underwent a standard 23gauge pars plana vitrectomy (PPV) (Constellation 23-Gauge System; Alcon, Inc., Hunenberg, Switzerland), under peribulbar or subtenon anesthesia. After standard PPV, conjunctival peritomy was performed at 3 o'clock and 9 o'clock along the limbus to expose the sclera. A limbus corneal incision of $2.4 \mathrm{~mm}$ was created at 12 o'clock position to insert the IOL into the anterior chamber using the injector. Care should be taken to ensure that the optic vaults posteriorly. One foldable haptic was then externalized through the corneal incision using forceps, and a double thread 10-0 or 9-0 polypropylene suture was passed through the eyelet of the haptic outside the eye. Afterwards, the needle was carefully inserted through the corneal incision, passed behind the 


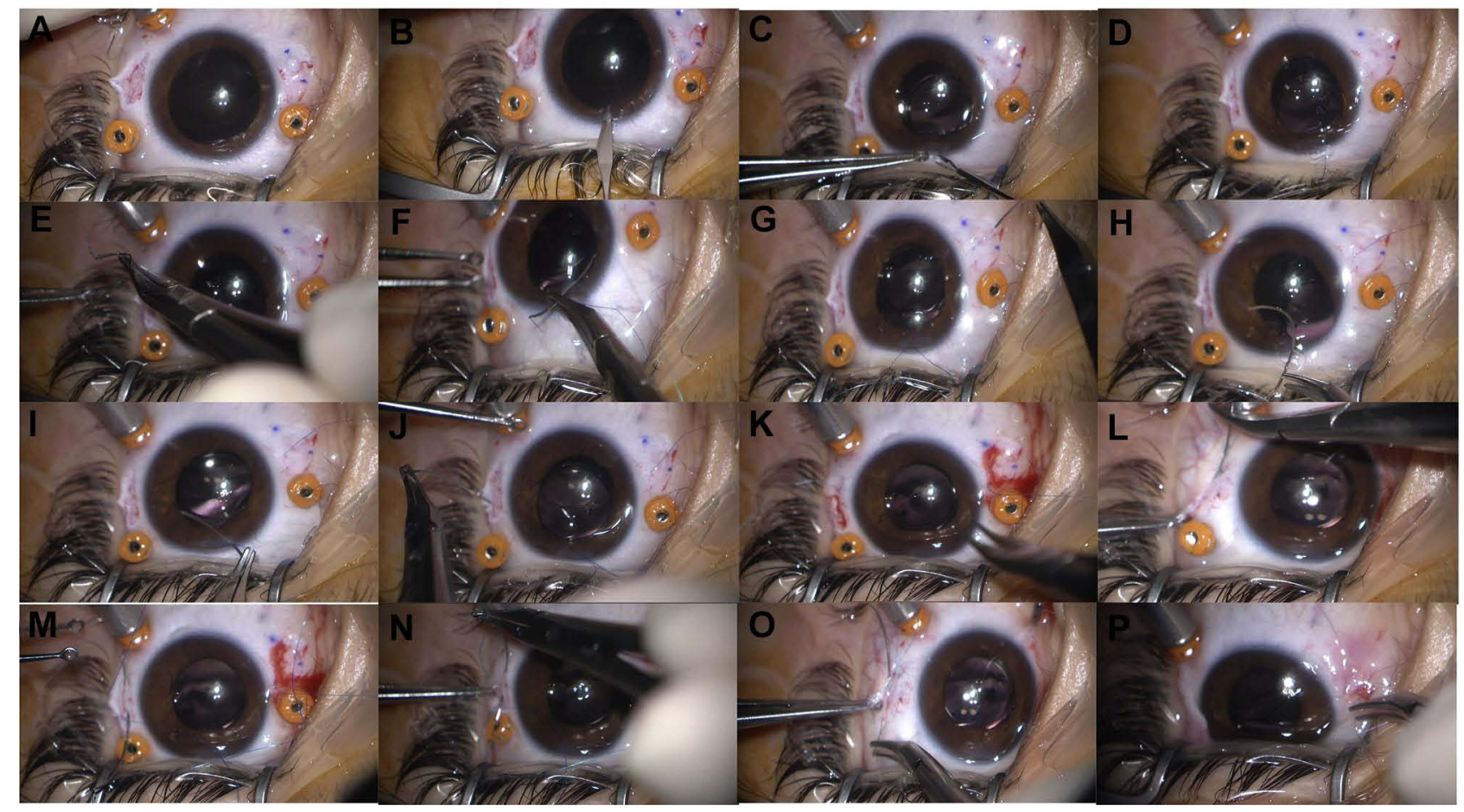

Figure I Intrascleral knotless zigzag suture fixation of Akreos AO60 foldable intraocular lens (IOL) technique. (A) Conjunctival peritomy at 3 and 9 o'clock to expose the sclera. (B) Limbus corneal incision at 12 o'clock. (C) One haptic is externalized through the corneal incision. (D) A double thread I0-0 or 9-0 polypropylene suture is passed through the eyelet. (E) The needle is passed between the arms of the thread. (F and $\mathbf{G})$ The needle is inserted through the corneal incision, passed behind the iris, and came out through the sclera at about $2 \mathrm{~mm}$ from the limbus. ( $\mathbf{H}$ and $\mathbf{J}$ ) The steps are repeated using the $180^{\circ}$ away haptic and orienting the needle to the opposite side. (K) Centration of the IOL. (L-O) The suture is run through the partial thickness of the sclera in a zigzag pattern (4 intrascleral passages), and the thread is cut flush to the sclera without knotting (this procedure is performed in the nasal and temporal sides). (P) Conjunctival suture.

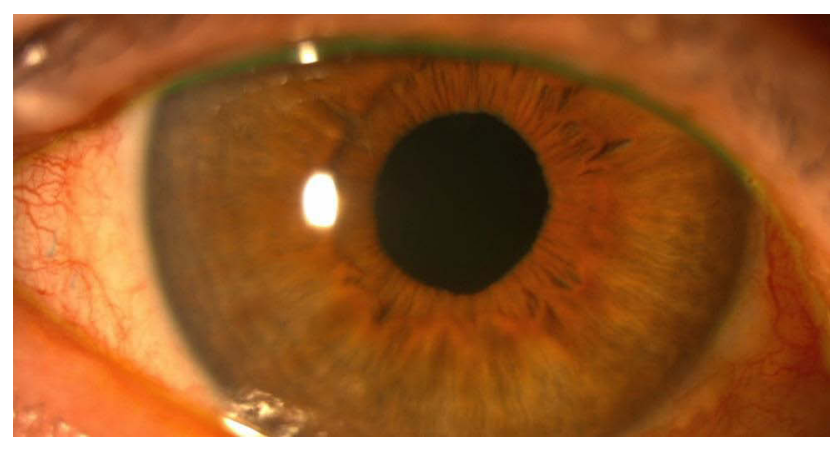

Figure 2 Postoperative slit-lamp photography of a patient that underwent intrascleral knotless zigzag suture fixation of Akreos AO60.

iris, and came out through the sclera at a distance of approximately $2 \mathrm{~mm}$ from the limbus in the nasal or temporal side. This ab interno maneuver was repeated using the $180^{\circ}$ away haptic and orienting the needle to the opposite side. The exit sites of the needle in the nasal and temporal sclera should be $180^{\circ}$ apart, and, ideally, in the 0 - to 180 -degree axis. By simultaneous pulling of the threads in both sides, the correct position and centration of the IOL was confirmed. Then, each suture was run through the partial thickness of the sclera in a zigzag pattern as described elsewhere. ${ }^{6}$ After four parallel intrascleral passages, the IOL was fixated and the thread was cut flush to the sclera without knotting. The conjunctival peritomy was closed with polyglactin (Vicryl) $8-0$, and the corneal incision was sealed with stromal hydration. Finally, the trocars were removed, and subconjunctival injection of antibiotic and steroids was given.

The standard procedure, as described above, was adapted according to the indication for surgery. In cases of subluxated IOL or complications related to anterior chamber IOL, the IOL was usually explanted. When the subluxated IOL was an Akreos AO60, the IOL was repositioned following the standard steps described. In cases of subluxated crystalline lens or cataract, either spontaneous or after trauma or complicated cataract surgery, a lensectomy was performed with the use of a vitrectomy cutter or phacoemulsification handpiece.

\section{Statistical Analysis}

Statistical analysis was performed using IBM SPSS Statistics 26. Categorical variables are summarized as absolute and relative frequency and continuous variables as mean 
and standard deviation. Shapiro-Wilk, KolmogorovSmirnov test and normal probability plots were used to confirm the normal distribution of the data. Parametric and nonparametric tests were used for comparison of continuous variables between groups, according to the normality of data. Comparisons of two categorical variables were made by using $\mathrm{X}^{2}$, and continuous variables using Student's or paired $t$-test (Mann-Whitney or Wilcoxon tests). Comparison among groups were performed using ANOVA test with homogeneity variance analysis, or non-parametric Kruskal-Wallis test. A p-value less than 0.05 was considered statistically significant.

\section{Results}

This study included 99 eyes of 92 patients: 53 with spontaneous IOL dislocation, 23 with intraoperatively complicated cataract surgery, 17 with traumatic natural lens or IOL dislocation, and 6 with other causes. In the last group, four had spontaneous natural lens dislocation, of which two had Marfan syndrome and two had corneal decompensation due to anterior chamber IOL in eyes without an adequate capsular support.

Baseline and surgical characteristics of study population are presented in Table 1 . The mean age was $72.1 \pm 15.2$ years (range 18-94) and the median follow-up duration was 19.5 months (range 3-81). Almost half of the cases $(46.5 \%, \mathrm{n}=46)$ had a follow-up longer than 12 months. The pseudoexfoliative syndrome was present in $43 \%(n=23)$ of eyes with spontaneous IOL dislocation. Overall, 51.5\% $(\mathrm{n}=51)$ had prior ocular history, and $15.2 \%(\mathrm{n}=15)$ had prior ocular surgery (excluding cataract surgery).

Among 56 cases with spontaneous or traumatic IOL dislocation, IOL was repositioned in 4 cases, and exchanged in the remaining. The mean surgical time was $47.8 \pm 17.0 \mathrm{~min}$. There were no differences in surgical time between study groups $(44.8 \pm 17.3 \mathrm{~min}$ in spontaneous IOL

Table I Baseline Characteristics of Study Population

\begin{tabular}{|c|c|c|c|c|c|c|}
\hline & All $(n=99)$ & $\begin{array}{l}\text { Spontaneous } \\
\text { IOL Dislocation } \\
(n=53)\end{array}$ & $\begin{array}{c}\text { Complicated } \\
\text { Cataract Surgery } \\
\qquad(n=23)\end{array}$ & $\begin{array}{l}\text { Traumatic Natural Lens } \\
\text { or IOL Dislocation } \\
(n=\mid 7)\end{array}$ & $\begin{array}{l}\text { Other } \\
\text { Causes* } \\
(n=6)\end{array}$ & p-value $\dagger$ \\
\hline Age, mean $\pm S D$ & $72.1 \pm 15.2$ & $74.9 \pm(14.5)$ & $73.8 \pm 16.3$ & $65.5 \pm 11.7$ & $60.0 \pm 16.7$ & 0.003 \\
\hline Male, n (\%) & $58(58.6)$ & $30(56.6)$ & $9(39.1)$ & $15(88.2)$ & $4(67)$ & 0.19 \\
\hline $\begin{array}{l}\text { Follow-up } \\
\text { (months), median } \\
\text { (range) }\end{array}$ & $19.5(3-81)$ & $21.3(3-8 I)$ & I7.| (3-59) & $13.0(3-48)$ & $30.0(5-69)$ & 0.322 \\
\hline $\begin{array}{l}\text { Baseline BCVA } \\
\text { (logmar), mean } \pm S D\end{array}$ & $1.34 \pm 0.70$ & $1.28 \pm 0.73$ & $1.51 \pm 0.68$ & $1.32 \pm 0.68$ & $1.35 \pm 0.60$ & 0.721 \\
\hline $\begin{array}{l}\text { Pseudoexfoliative } \\
\text { syndrome }\end{array}$ & 29 (29.3\%) & $23(43.4 \%)$ & 6 (11.3\%) & $0(0.0 \%)$ & $0(0.0 \%)$ & NA \\
\hline Glaucoma & $13(13.1 \%)$ & $10(18.9 \%)$ & $2(8.7 \%)$ & I (5.9\%) & $0(0.0 \%)$ & NA \\
\hline $\begin{array}{l}\text { Diabetic } \\
\text { retinopathy }\end{array}$ & $6(6.1 \%)$ & $5(9.4 \%)$ & I (4.3\%) & $0(0.0 \%)$ & $0(0.0 \%)$ & NA \\
\hline Retinal detachment & $4(4.0 \%)$ & I (I.9\%) & $0(0.0 \%)$ & I (5.9\%) & $2(33.3 \%)$ & NA \\
\hline Uveitis $\ddagger$ & $3(3.0 \%)$ & $3(5.7 \%)$ & $0(0.0 \%)$ & $0(0.0 \%)$ & $0(0.0 \%)$ & NA \\
\hline Others diseases** & 17 (17.0\%) & $12(22.6 \%)$ & $4(17.4 \%)$ & I (5.9\%) & $0(0.0 \%)$ & NA \\
\hline $\begin{array}{l}\text { Prior ocular } \\
\text { surgery**** }\end{array}$ & 15 (15.2\%) & $9(17.0 \%)$ & $2(8.7 \%)$ & I (5.9\%) & $3(50.0 \%)$ & NA \\
\hline
\end{tabular}

Notes: *Including spontaneous natural lens dislocation ( $n=4,2$ of them with Marfan syndrome), and corneal decompensation due to anterior chamber IOL in eyes without capsular support $(\mathrm{n}=2)$.**Including pigmentary retinitis, epiretinal membrane, age-related macular degeneration, high myopia, Fuchs dystrophy, and strabismus. ***Including pars plana vitrectomy, refractive surgery, corneal transplant and glaucoma surgery. ${ }^{\ddagger}$ Including 2 cases of uveitis-glaucoma-hyphaema syndrome after scleral fixation of AcrySof SN60WF IOL. ${ }^{\dagger}$ Comparison between intraoperatively complicated cataract surgery, complicated cataract surgery, traumatic natural lens or IOL dislocation, and other causes.

Abbreviations: SD, standard deviation; IOL, intraocular lens; VEGF, vascular endothelial growth factor; NA, non-applicable. 
dislocation, $52.3 \pm 18.6 \mathrm{~min}$ in complicated cataract surgery, $50.0 \pm 15.1 \mathrm{~min}$ in traumatic natural lens or IOL dislocation, $50.4 \pm 10.5 \mathrm{~min}$ in other causes, $\mathrm{p}=0.317$ ).

The visual and refractive surgical outcomes are shown in Table 2. The BCVA improved from a mean \pm SD of 1.34 $\pm 0.70 \log \mathrm{MAR}$ at baseline to $0.49 \pm 0.56 \log \mathrm{MAR}$ at the end of follow-up $(p<0.001)$. The mean \pm SD final SE was $-1.24 \pm 1.82$ diopters. The mean $\pm \mathrm{SD}$ prediction error was $-0.51 \pm 1.16$ diopters and the median (range) absolute error was 0.62 diopters $(0.02-4.06)$.

The overall perioperative complications rate was $44.4 \%(n=44)$, as shown in Figure 3. This rate was $41.5 \%(n=22)$ in cases of spontaneous IOL dislocation, $56.5 \%(\mathrm{n}=13)$ in cases of complicated cataract surgery, $35.3 \%(\mathrm{n}=6)$ in cases of traumatic natural lens or IOL dislocation, and $50.0 \%(n=3)$ in other causes $(p=0.533$, no differences between groups). The rate of complications requiring invasive treatment (intravitreal injection or surgery) was $19.2 \%(n=19)$ in total sample. The type of perioperative complications is detailed in Table 3.

The most common perioperative complications were ocular hypertension (OHT, 20.2\%, $\mathrm{n}=20$ ), and cystoid macular edema (CME, 15.2\%, $\mathrm{n}=15$ ). Eighty-five percent $(n=17)$ of eyes with OHT after surgery had no previous history of glaucoma or OHT, and all of them were controlled with topical medication. Among 13 patients with previous history of glaucoma, $38.5 \%(\mathrm{n}=5)$ underwent glaucoma surgery after implantation of SFIOL, after a median period of 14 months (range 3-51). None of 15 cases of CME had prior ocular surgery or diabetic retinopathy, and $13.3 \%(n=2)$ of them required steroid intravitreal injection.

The rate of IOL dislocation was $7 \%(n=7)$. Of these, two were submitted to a second surgery which consisted of re-fixation of IOL with zigzag technique. Goretex ${ }^{\circledR}$ suture was used in one of the two cases. Three cases had IOL haptic dislocation into the anterior chamber, and all of them were also surgically approached. One case of IOL dislocation occurred in a patient with Marfan syndrome.

Other complications were less common, such as pseudophakic bullous keratopathy $(3 \%, n=3)$, endophthalmitis $(1 \%, \mathrm{n}=1)$, uveitis-glaucoma-hyphaema syndrome $(1 \%$, $\mathrm{n}=1)$, iridodialysis $(1 \%, \mathrm{n}=1)$, corneal leakage $(1 \%, \mathrm{n}=1)$, iris herniation $(1 \%, \mathrm{n}=1)$, and retained cortex fragments $(1 \%, n=1)$.

There were no differences in perioperative complications rate between eyes with or without previous ocular diseases $(45.1 \%$ vs $43.8 \%, \mathrm{p}=0.893)$.

\section{Discussion}

Over the years, many alternatives for IOL implantation without capsular support have been developed, ${ }^{19}$ including

Table 2 Visual and Refractive Surgical Outcomes

\begin{tabular}{|c|c|c|c|c|c|c|}
\hline & All $(n=99)$ & $\begin{array}{l}\text { Spontaneous IOL } \\
\text { Dislocation } \\
(n=53)\end{array}$ & $\begin{array}{c}\text { Intraoperatively } \\
\text { Complicated Cataract } \\
\text { Surgery }(n=23)\end{array}$ & $\begin{array}{l}\text { Traumatic Natural } \\
\text { Lens or IOL } \\
\text { Dislocation } \\
(n=17)\end{array}$ & $\begin{array}{l}\text { Other } \\
\text { Causes } \\
(n=6)\end{array}$ & p-value $\dagger$ \\
\hline $\begin{array}{l}\text { BCVA (logmar), } \\
\text { mean } \pm S D\end{array}$ & $0.49 \pm 0.56$ & $0.48 \pm 0.5 \mathrm{I}$ & $0.5 I \pm 0.63$ & $0.54 \pm 0.7$ I & $0.37 \pm 0.29$ & 0.928 \\
\hline $\begin{array}{l}\text { BCVA variation } \\
\text { (logmar), mean } \pm S D\end{array}$ & $-0.87 \pm 0.79$ & $-0.79 \pm 0.78$ & $-1.04 \pm 0.83$ & $-0.85 \pm 0.82$ & $-0.98 \pm 0.76$ & $0.74 I$ \\
\hline $\begin{array}{l}\text { Cylinder error (D), } \\
\text { mean } \pm S D\end{array}$ & $1.43 \pm 1.35$ & $1.62 \pm 1.45$ & $1.14 \pm 1.15$ & $|| 7 \pm 1.4 \mid$. & $1.43 \pm 0.84$ & 0.290 \\
\hline $\begin{array}{l}\text { Spherical equivalent } \\
\text { (D), mean } \pm S D\end{array}$ & $-1.24 \pm 1.82$ & $-1.50 \pm 1.58$ & $-0.70 \pm 2.25$ & $-1.09 \pm 2.08$ & $-1.33 \pm 1.39$ & 0.424 \\
\hline $\begin{array}{l}\text { Prediction error } \\
\text { (D), mean } \pm S D\end{array}$ & $-0.51 \pm 1.16$ & $-0.65 \pm 1.08$ & $-0.40 \pm 1.52$ & $-0.14 \pm 0.88$ & $-1.05 \pm 1.15$ & 0.545 \\
\hline $\begin{array}{l}\text { Absolute } \\
\text { prediction error } \\
\text { (D), mean } \pm S D\end{array}$ & $0.92 \pm 0.87$ & $0.95 \pm 0.81$ & $1.09 \pm 1.00$ & $0.58 \pm 0.64$ & $1.22 \pm 1.04$ & 0.468 \\
\hline
\end{tabular}

Notes: ${ }^{\dagger}$ Comparison between intraoperatively complicated cataract surgery, complicated cataract surgery, traumatic natural lens or IOL dislocation, and other causes. Abbreviations: BCVA, best corrected visual acuity; IOL, intraocular lens; D, diopters. 


\section{Perioperative complications rate}

-All $\quad$ Requiring invasive treatment
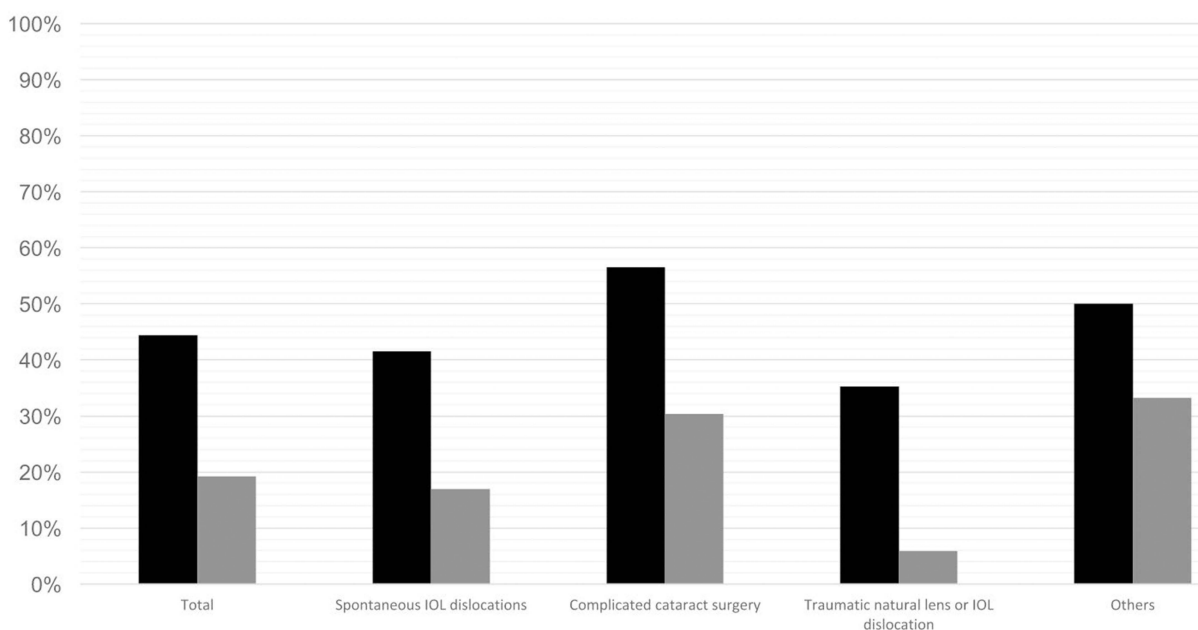

dislocation

Figure 3 Perioperative complications rate.

anterior chamber IOL, IFIOL and SFIOL. So far, there is insufficient evidence to recommend any strategy over any other for patients suitable for all three options. ${ }^{15}$ Scleral fixation of an IOL allows for a more physiological retroiris positioning and avoids damage to the endothelial cells and angle structures. ${ }^{19-21}$ In this study, we report our experience with a new technique of scleral fixation of an IOL, consisting of a zigzag suture fixation of the four- haptic hydrophilic acrylic foldable Akreos AO60. This IOL is intended for placement in the capsular bag, but "off-label" use of Akreos AO60 as a SFIOL has been previously reported. ${ }^{14,22-24}$ In our series, all surgeries were performed by posterior segment surgeons.

Yamane et $\mathrm{al}^{9}$ and Barca et $\mathrm{al}^{25}$ presented the mean refractive difference from the predicted value by the Sanders-Retzlaff-Kraff trial formula for in-the-bag fixation

Table 3 Perioperative Complications

\begin{tabular}{|c|c|c|c|c|c|}
\hline & All $(n=99)$ & $\begin{array}{c}\text { Spontaneous } \\
\text { IOL Dislocation } \\
(n=53)\end{array}$ & $\begin{array}{c}\text { Intraoperatively } \\
\text { Complicated Cataract } \\
\text { Surgery }(n=23)\end{array}$ & $\begin{array}{l}\text { Traumatic Natural Lens } \\
\text { or IOL Dislocation } \\
(n=\mid 7)\end{array}$ & $\begin{array}{c}\text { Other } \\
\text { Causes } \\
(n=6)\end{array}$ \\
\hline Ocular hypertension & $20(20.2 \%)$ & II (20.8\%) & $5(21.7 \%)$ & $3(17.6 \%)$ & I (I6.7\%) \\
\hline Cystoid macular edema & 15 (I5.2\%) & $6(11.3 \%)$ & $5(21.7 \%)$ & $3(17.6 \%)$ & I (I6.7\%) \\
\hline IOL dislocation & 7 (7.0\%) & $3(5.7 \%)$ & $2(8.7 \%)$ & I (5.6\%) & I (I6.7\%) \\
\hline $\begin{array}{l}\text { Pseudophakic bullous } \\
\text { keratopathy }\end{array}$ & $3(3.0 \%)$ & $2(3.8 \%)$ & I (4.3\%) & $0(0.0 \%)$ & $0(0.0 \%)$ \\
\hline Endophthalmitis & I (I.0\%) & $0(0.0 \%)$ & I (4.3\%) & $0(0.0 \%)$ & $0(0.0 \%)$ \\
\hline $\begin{array}{l}\text { Uveitis-glaucoma-hyphaema } \\
\text { syndrome }\end{array}$ & I (I.0\%) & I (I.9\%) & $0(0.0 \%)$ & $0(0.0 \%)$ & $0(0.0 \%)$ \\
\hline Iridodialysis & I (I.0\%) & I (I.9\%) & $0(0.0 \%)$ & $0(0.0 \%)$ & $0(0.0 \%)$ \\
\hline Iris herniation & $\mathrm{I}(\mathrm{I} .0 \%)$ & $0(0.0 \%)$ & I (4.3\%) & $0(0.0 \%)$ & $0(0.0 \%)$ \\
\hline Corneal leakage & $\mathrm{I}(\mathrm{I} .0 \%)$ & $\mathrm{I}(\mathrm{I} .9 \%)$ & $0(0.0 \%)$ & $0(0.0 \%)$ & $0(0.0 \%)$ \\
\hline Retained lens fragments & I (I.0\%) & $0(0.0 \%)$ & $0(0.0 \%)$ & $0(0.0 \%)$ & $0(0.0 \%)$ \\
\hline
\end{tabular}

Abbreviation: IOL, intraocular lens. 
and that was $-0.21 \pm 0.99 \mathrm{D}$ and $-0.24 \pm 0.81 \mathrm{D}$, respectively. Those authors used sutured ${ }^{9}$ and plugs-fixated IOL. ${ }^{25}$ Those values were slightly lower than the mean prediction error obtained in our series. However, the difference between studies is less than 0.5 diopters. Brunin et $\mathrm{al}^{26}$ reported that $35 \%$ of the patients with transscleral-sutured intraocular lens fell within $\pm 0.5 \mathrm{D}$ of refractive prediction error, whereas $65 \%$ were within $\pm 1.0 \mathrm{D}$. Overall, our refractive results are in agreement with those reported in the literature.

This technique offers several advantages. Fixing the external suture to the sclera is quick and easy to perform with minimal opening of the conjunctiva. The use of a suture instead of haptics fixation as performed in other techniques $^{8,9,27}$ maintains the integrity of the IOL and enables a less destructive fixation for the sclera and conjunctiva. The knotless approach is another positive feature as knots may lead to scleral atrophy and conjunctival erosion, increasing the risk of endophthalmitis as the suture provides a direct route for exogenous bacteria to enter the eye. ${ }^{28-30}$ This technique also avoids the use of scleral grooves and flaps, which delay but not prevent suture erosion. ${ }^{31}$ Another important advantage is the safety and reliability of the suture fixation within the sclera. In this series, both 10-0 and 9-0 polypropylene sutures were used and seven cases of IOL dislocation ( 3 were IOL haptic dislocation into the anterior chamber) are described, with 1 of them being re-fixated with a Goretex suture. Several studies pointed out that IOL dislocation can occur years after implantation when 10-0 polypropylene is used. ${ }^{32,33}$ Thus, there is a trend towards a more frequent resource of 9-0 sutures as the risk of degradation and secondary IOL shift is minor. ${ }^{34}$

One limitation of this technique is the discard of two of the four haptics of Akreos AO60, increasing the risk of lens tilt and decentration. It has been shown that lens tilt of just $5^{\circ}$ can induce additional refractive error ${ }^{35}$ and if $>15^{\circ}$ can lead to high-order aberrations that cannot be corrected with glasses. ${ }^{36}$ Another limitation related to the lens material as the Akreos AO60 is hydrophilic and thus more prone to optic opacification via calcium salt deposition following intraocular gas or air fill. ${ }^{37}$ In this series, almost half of the patients had at least one complication and $20 \%$ had a complication requiring invasive treatment. The most common complications were cystoid macular edema and ocular hypertension. These rates are substantially higher than some series ${ }^{9,25}$ but similar to others. ${ }^{38}$ No cases of ocular hypotony are hereby reported. Of note, this complication was more frequent than hypertension with haptic-fixation techniques. ${ }^{9,39}$ Kam et $\mathrm{al}^{38}$ reported early ocular hypertension and vitreous hemorrhage to be more frequent following SFIOL implantation without concurrent PPV. In our series, all patients were vitrectomized, which explains the lower rate of vitreous hemorrhage. Ocular hypertension may be explained by iris rubbing and consequent pigment dispersion. Among patients with glaucoma, 38.5\% needed glaucoma surgery after Akreos AO60 scleral fixation. Thus, the overall risk-benefit must be well balanced as other techniques may be safer for these patients.

In 2003, an American Academy of Ophthalmology report showed that $80.5 \%$ of the eyes with SFIOL after complicated cataract surgery achieved BCVA of 20/40 or better, while $4.9 \%$ had BCVA of $20 / 200$ or worse. ${ }^{40}$ In our series, the results were $54.5 \%$ and $19.2 \%$ for final BCVA $\geq 20 / 40$ and $\leq 20 / 200$, respectively. However, we present a consecutive case series without exclusion of patients based on etiology or ocular pathology. Moreover, in this study, half of the patients had prior ocular history.

This study has some limitations. This is a single-center study that assessed the results of several surgeons with variable lengths of follow-up. Its retrospective nature with all the drawbacks associated does not allow to assess all variables intended, including the tilt. Due to inclusion of all consecutive patients, our sample is heterogenous - this gives us a real-world idea of this technique performance but limits the comparison with other studies that select patients based on cause or previous ophthalmic history.

\section{Conclusion}

In patients without adequate capsular support to allow inthe-bag or sulcus placement of an IOL, scleral fixation is an effective approach. This knotless technique avoids the risks of haptics fixation but is more prone to IOL dislocation in cases of suture deterioration. The most common postoperative complications were macular edema and ocular hypertension. Almost $40 \%$ of the patients with previous glaucoma ended up needing glaucoma surgery due to uncontrolled ocular hypertension. Therefore, past ophthalmic history needs to be carefully considered in candidates who underwent SFIOL implantation.

\section{Ethics}

The study was conducted according to the tenets of the Declaration of Helsinki in its latest amendment (Brazil, 2013) and was approved by the local IRB ("Departamento de Ensino, Formação e Investigação"). 


\section{Informed Consent}

All patients signed an informed consent form.

\section{Acknowledgment}

The abstract of this paper was presented at the 2019 EVRS Congress - Lisbon as a poster presentation with interim findings.

\section{Author Contributions}

All authors made a significant contribution to the work reported, whether that is in the conception, study design, execution, acquisition of data, analysis and interpretation, or in all these areas; took part in drafting, revising or critically reviewing the article; gave final approval of the version to be published; have agreed on the journal to which the article has been submitted; and agree to be accountable for all aspects of the work.

\section{Disclosure}

The authors report no conflicts of interest in this work.

\section{References}

1. Lyle WA, Jin JC. Secondary intraocular lens implantation: anterior chamber vs posterior chamber lenses. Ophthalmic Surg. 1993;24 (6):375-381.

2. Melamud A, Topilow JS, Cai L, He X. Pars plana vitrectomy combined with either secondary scleral-fixated or anterior chamber intraocular lens implantation. Am J Ophthalmol. 2016;168:177-182. doi:10.1016/j.ajo.2016.05.006

3. Kim KH, Kim WS. Comparison of clinical outcomes of iris fixation and scleral fixation as treatment for intraocular lens dislocation. $\mathrm{Am}$ $J$ Ophthalmol. 2015;160(3):463-469 e461. doi:10.1016/j. ajo.2015.06.010

4. Long C, Wei Y, Yuan Z, Zhang Z, Lin X, Liu B. Modified technique for transscleral fixation of posterior chamber intraocular lenses. $B M C$ Ophthalmol. 2015;15:127. doi:10.1186/s12886-015-0118-8

5. Wilgucki JD, Wheatley HM, Feiner L, Ferrone MV, Prenner JL. Oneyear outcomes of eyes treated with a sutureless scleral fixation technique for intraocular lens placement or rescue. Retina. 2015;35 (5):1036-1040. doi:10.1097/IAE.0000000000000431

6. Szurman P, Petermeier K, Aisenbrey S, Spitzer MS, Jaissle GB. Z-suture: a new knotless technique for transscleral suture fixation of intraocular implants. $B r \quad J \quad$ Ophthalmol. 2010;94(2):167-169. doi:10.1136/bjo.2009.162180

7. Botsford BW, Williams AM, Conner IP, Martel JN, Eller AW. Scleral fixation of intraocular lenses with gore-tex suture: refractive outcomes and comparison of lens power formulas. Ophthalmol Retina. 2019;3 (6):468-472. doi:10.1016/j.oret.2019.02.005

8. Agarwal A, Kumar DA, Jacob S, Baid C, Agarwal A, Srinivasan S. Fibrin glue-assisted sutureless posterior chamber intraocular lens implantation in eyes with deficient posterior capsules. $J$ Cataract Refract Surg. 2008;34(9):1433-1438. doi:10.1016/j.jcrs.2008.04.040

9. Yamane S, Sato S, Maruyama-Inoue M, Kadonosono K. Flanged intrascleral intraocular lens fixation with double-needle technique. Ophthalmology. 2017;124(8):1136-1142. doi:10.1016/j. ophtha.2017.03.036
10. Al-Qahtani FA. Scleral fixation of intraocular lenses combined with penetrating keratoplasty. $J$ Cataract Refract Surg. 2010;36 (3):373-376. doi:10.1016/j.jcrs.2009.09.041

11. Gabor SG, Pavlidis MM. Sutureless intrascleral posterior chamber intraocular lens fixation. $J$ Cataract Refract Surg. 2007;33 (11):1851-1854. doi:10.1016/j.jcrs.2007.07.013

12. Boral SK, Agarwal D. A simple modified way of glueless, sutureless scleral fixation of an IOL: a retrospective case series. $\mathrm{Am}$ J Ophthalmol. 2020;218:314-319. doi:10.1016/j.ajo.2020.03.021

13. Ting Yip L, Fong A, Wai Tsang C. A novel technique for 27-gauge forceps assisted transcleral refixation of dislocated CZ70BD intraocular lens. Retina. 2021. doi:10.1097/IAE.00000000000003225

14. Fass ON, Herman WK. Four-point suture scleral fixation of a hydrophilic acrylic IOL in aphakic eyes with insufficient capsule support. J Cataract Refract Surg. 2010;36(6):991-996. doi:10.1016/j. jcrs.2009.12.043

15. Veronese C, Maiolo C, Armstrong GW, et al. New surgical approach for sutureless scleral fixation. Eur $J$ Ophthalmol. 2020;30 (3):612-615. doi:10.1177/1120672120902020

16. Lange C, Feltgen N, Junker B, Schulze-Bonsel K, Bach M. Resolving the clinical acuity categories "hand motion" and "counting fingers" using the Freiburg Visual Acuity Test (FrACT). Graefes Arch Clin Exp Ophthalmol. 2009;247(1):137-142. doi:10.1007/s00417-0080926-0

17. Holladay JT. Proper method for calculating average visual acuity. $J$ Refract Surg. 1997;13(4):388-391. doi:10.3928/1081-597X-1997 0701-16

18. Akreos I. Bausch \& Lomb; 2021. Available from: https://www. bausch.com/ecp/our-products/cataract-surgery/lens-systems/akreosao. Accessed September 4th, 2021.

19. Menapace R, Findl O, Georgopoulos M, Rainer G, Vass C, Schmetterer K. The capsular tension ring: designs, applications, and techniques. J Cataract Refract Surg. 2000;26(6):898-912. doi:10.1016/S0886-3350(00)00446-6

20. Mora P, Calzetti G, Favilla S, et al. Comparative analysis of the safety and functional outcomes of anterior versus retropupillary Iris-Claw IOL fixation. $J$ Ophthalmol. 2018;2018:8463569. doi:10.1155/2018/8463569

21. Por YM, Lavin MJ. Techniques of intraocular lens suspension in the absence of capsular/zonular support. Surv Ophthalmol. 2005;50 (5):429-462. doi:10.1016/j.survophthal.2005.06.010

22. Fass ON, Herman WK. Sutured intraocular lens placement in aphakic post-vitrectomy eyes via small-incision surgery. $J$ Cataract Refract Surg. 2009;35(9):1492-1497. doi:10.1016/j.jcrs.2009.04.034

23. Khan MA, Rahimy E, Gupta OP, Hsu J. Combined 27-gauge pars plana vitrectomy and scleral fixation of an akreos ao60 intraocular lens using gore-tex suture. Retina. 2016;36(8):1602-1604. doi:10.1097/IAE.0000000000001147

24. Khan MA, Gupta OP, Smith RG, et al. Scleral fixation of intraocular lenses using Gore-Tex suture: clinical outcomes and safety profile. $\mathrm{Br}$ $J$ Ophthalmol. 2016;100(5):638-643. doi:10.1136/bjophthalmol2015-306839

25. Barca F, Caporossi T, de Angelis L, et al. Trans-scleral plugs fixated IOL: a new paradigm for sutureless scleral fixation. $J$ Cataract Refract Surg. 2020;46(5):716-720. doi:10.1097/j.jcrs.000000 0000000135

26. Brunin G, Sajjad A, Kim EJ, et al. Secondary intraocular lens implantation: complication rates, visual acuity, and refractive outcomes. J Cataract Refract Surg. 2017;43(3):369-376. doi:10.1016/j.jcrs.2016.12.024

27. Rodriguez-Agirretxe I, Acera-Osa A, Ubeda-Erviti M. Needle-guided intrascleral fixation of posterior chamber intraocular lens for aphakia correction. J Cataract Refract Surg. 2009;35(12):2051-2053. doi:10.1016/j.jcrs.2009.06.044

28. Kang HM, Chung EJ. Late-onset Citrobacter koseri endophthalmitis with suture exposure after secondary intraocular lens implantation. Korean J Ophthalmol. 2011;25(4):285-288. doi:10.3341/kjo.2011.25.4.285 
29. Schechter RJ. Suture-wick endophthalmitis with sutured posterior chamber intraocular lenses. J Cataract Refract Surg. 1990;16 (6):755-756. doi:10.1016/S0886-3350(13)81021-8

30. Heilskov T, Joondeph BC, Olsen KR, Blankenship GW. Late endophthalmitis after transscleral fixation of a posterior chamber intraocular lens. Arch Ophthalmol. 1989;107(10):1427. doi:10.1001/ archopht.1989.01070020501017

31. Lewis JS. Sulcus fixation without flaps. Ophthalmology. 1993;100 (9):1346-1350. doi:10.1016/S0161-6420(93)31477-6

32. Buckley EG. Safety of transscleral-sutured intraocular lenses in children. $J$ AAPOS. 2008;12(5):431-439. doi:10.1016/j. jaapos.2008.04.016

33. Price MO, Price FW Jr, Werner L, Berlie C, Mamalis N. Late dislocation of scleral-sutured posterior chamber intraocular lenses. $J$ Cataract Refract Surg. 2005;31(7):1320-1326. doi:10.1016/j. jcrs.2004.12.060

34. Wu Z, Liu C, Xu Y, Dong W, Chen Z. Modified technique for scleral-sutured fixation with the double knots technique for posterior chamber intraocular lens: short-term observation. J Ophthalmol. 2021;2021:6697230. doi:10.1155/2021/6697230

35. Tsai YY, Tseng SH. Transscleral fixation of foldable intraocular lens after pars plana lensectomy in eyes with a subluxated lens. J Cataract Refract Surg. 1999;25(5):722-724. doi:10.1016/S0886-3350(99)00019-X
36. Holladay JT. Evaluating the intraocular lens optic. Surv Ophthalmol. 1986;30(6):385-390. doi:10.1016/0039-6257(86)90092-5

37. Cao D, Zhang H, Yang C, Zhang L. Akreos Adapt AO Intraocular lens opacification after vitrectomy in a diabetic patient: a case report and review of the literature. BMC Ophthalmol. 2016;16:82. doi:10.1186/s12886-016-0268-3

38. Kam KW, Chan YFA, Yu M, Ho M, Young AL. Outcomes and complications in scleral-fixated intraocular lens implantations. Int Ophthalmol. 2020;40(11):2969-2977. doi:10.1007/s10792-02001480-8

39. Agarwal L, Agarwal N, Gurung RL, Chaubey R, Jha BK, Chaudhary BP. Visual outcome and early complications of sutureless and glueless scleral fixated intraocular lens. Nepal J Ophthalmol. 2016;8(15):41-46. doi:10.3126/nepjoph.v8i1.16155

40. Wagoner MD, Cox TA, Ariyasu RG, Jacobs DS, Karp CL. Intraocular lens implantation in the absence of capsular support: a report by the American Academy of Ophthalmology. Ophthalmology. 2003;110(4):840-859. doi:10.1016/S0161-6420(02) 02000-6
Clinical Ophthalmology

\section{Publish your work in this journal}

Clinical Ophthalmology is an international, peer-reviewed journal covering all subspecialties within ophthalmology. Key topics include: Optometry; Visual science; Pharmacology and drug therapy in eye diseases; Basic Sciences; Primary and Secondary eye care; Patient Safety and Quality of Care Improvements. This journal is indexed on PubMed
Dovepress

Central and CAS, and is the official journal of The Society of Clinical Ophthalmology (SCO). The manuscript management system is completely online and includes a very quick and fair peer-review system, which is all easy to use. Visit http://www.dovepress.com/ testimonials.php to read real quotes from published authors. 